\title{
A agência para aplicação de energia de São Paulo
}

\section{JOSE ZATZ}

Gerente-geral da Agência para Aplicação de Energia de São Paulo. Engenheiro eletricista pela Escola Politécnica e f́́sico nuclear pela Universidade de Sāo Paulo; doutor em Física Nuclear pela Universidade de Paris; professor do Instituto de Fisica da USP; foi pesquisador associado no Centro Nuclear de Saclay, na França, e no Centro Europeu de Pesquisas Nucleares em Genebra, na Suiça. É membro do Conselho Estadual de Energia do Estado de Såo Paulo e do Conselho Estadual de Ciência e Tecnologia do mesmo Estado.

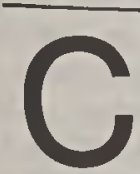

om os excedentes de eletricidade disponiveis a partir de 1981, em função de condiçōes hidrológicas favoráveis e da redução do consumo em virtude de desativação econômica do pals, formalizou-se uma política de substituição de derivados de petróleo por energia elétrica.

O Setor Elétrico, ao mesmo tempo, redefiniu sua política de vendas de eletricidade, procurando impor uma maior agressividade à conquista de novas fatias do mercado forçadas pela necessidade de substituir combustíveis importados.
Consciente desse quadro, ao assumir, - governo Montoro através da unificação da Presidência das suas empresas de energia - CESP, CPFL e ELETROPAULO, sob a presidência do Prof. José Goldem. berg, estabeleceu um planejamento global de ação, que objetivou prestar todo apoio aos consumidores no sentido de uma maior adequação destes aos diversos energéticos disponiveis no Estado.

Foi criada então a Agência para Aplicação de Energia, ligada à Presidência da CESP, CPFL, ELETROPAULO e mais recentemente da COMGÁS, com a finalidade de desenvolver e coordenar programas voltados à aplicação de energia.

Mais exatamente, a função da Agência é promover a utilização racional da energia no Estado de São Paulo, através de ações que beneficiem as empresas de energia, o mercado consumidor $e$ a sociedade em geral, adequando cada forma de energia às características do setor ou subsetor em que ela será empregada.

Sua meta fundamental é orientar o mercado para que cada um receba a energia que se adapte melhor às suas necessidades, que seja a mais barata para aquele tipo de atividade, que contamine menos o ambiente, que permita gerar

\section{FIGURA 1}

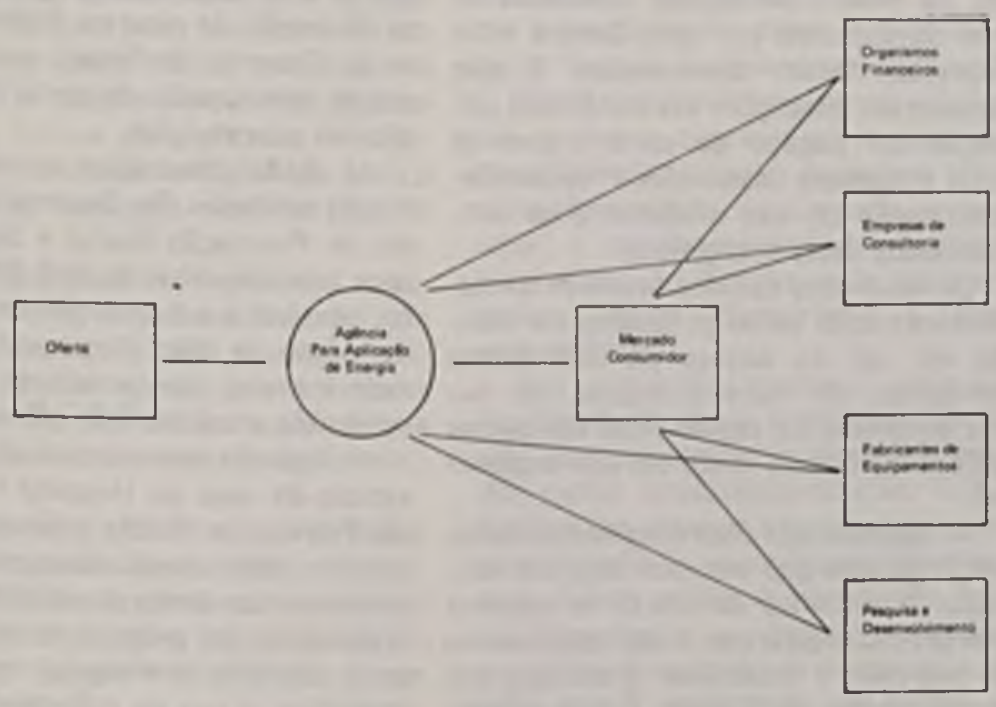

novos empregos, que permita resolver ou, pelo menos, auxiliar na solução de uma série de problemas da sociedade como um todo.

A Figura 1 permite uma melhor visualização do papel da Agência para Aplicação de Energia.

No lado esquerdo observarmos uma caixa correspondendo à "oferta"; no meio, a Agência para Aplicação de Energia, à sua direita uma outra caixa representando o "mercado consumidor", e mais à direita, quatro blocos: "organismos financeiros", "empresas de consul. toria", "fabricantes de equipamentos". "pesquisa e desenvolvimento". A função da Agência é fazer com que essa "orquestra" trabalhe harmonicamente; com que a oferta e o mercado consumidor se integrem entre si da melhor maneira possivel.

No sentido de desempenhar cada vez melhor o seu papel, a Agência necessita ter um conhecimento crescente, principalmente do mercado consumidor, saber qual é o perfil deste ou daquele setor, em que atividade, dentro do setor, se consome mais ou menos energia, qual é o tipo de equipamento utilizado, qual a eficiência desse equipamento e qual a sua origem.

Para isso, evidentemente, a Agência tem que estar voltada como um "radar" para o mercado propriamente dito, ou seja, os consumidores. Mas deve também, conhecer em cada setor (industrial, residencial, comercial, etc.) o tipo de equipamento que se usa, qual o consumo de energia, quais os energéticos utilizados, em suma, todos os aspectos vinculados direta ou indiretamente ao fornecimento de energia. Deve acompanhar também os programas de financiamento que existem e que podem auxiliar o consumidor em eventuais transformaçōes ou substituiçōes, quais os fabricantes de equipamentos que estão produzindo ou que poderão produzir equipamentos que aumentem a racionalidade no uso, quais as áreas prioritárias de pesquisa e desenvolvimento, que tecnologias utilizadas com sucesso em outros paises poderiam ser trazidas para cá e tornar-se disponíveis. 
O papel da Agéncia é fazer esse grande múltiplo casamento. Um múltiplo casamento no sentido de que os interesses de todas as partes sejam satisfeitos.

Abordaremos, a seguir, alguns programas que a Agência já tem ou que está desenvolvendo para atingir esses objetivos.

Para melhor direcionar suas ações a Agência vem expandindo seu sistema de informação propiciando a implementação de ações baseadas num conhecimento mais concreto e atualizado do mercado de energia. Neste contexto, foi implantado o SICEN - Sistema de Informações dos Consumidores do Energia, que reúne em um banco de dados de acesso imediato, informações até então dispersas e desatualizadas sobre o consumo energético no Estado de São Pau10.

Numa primeira etapa, deu-se prioridade ao Setor Industrial, responsável pela maior parcela do consumo de energia.

Em conjunto com as concessionárias de energia elétrica do Estado foi realizada uma pesquisa de campo junto a cerca de 1.100 indústrias, responsáveis, no conjunto, por $85 \%$ do consumo de óleos combustiveis em São Paulo. Nessas pesquisas foram levantandos os consumos de todos os energéticos utilizados por essas indústrias, bem como as caracteristicas dos equipamentos consumidores.

No Programa de Substituiç̃o de de. rivados de petróleo, a Agência buscou inicialmente difundir a eletrotermia através de atendimento direto aos consumidores industriais, campanhas de divulgação, seminários, cursos e palestras dirigidos a associações de classe, sindicatos patronais e empresas, procurando mostrar que a viabilidade da utilização da eletricidade para geração de calor, não se prende apenas à tarifação especial proporcionada pelo excedente sazonal de energia elétrica, mas também à eficiéncia energética dos processos eletrotérmicos.

Na comercialização da EGTD - Ener. gia Garantida por Tempo Determinado, os esforços da Agência e das concessionárias de energia elétrica paulistas permitiram colocar no mercado, praticamente sem investimento, num periodo de menos de 3 anos, uma potência de $1.650 \mathrm{MW}$, aproximadamente 3 vezes maior que a potência nominal da usina nuclear de Angra dos Reis, e obter uma economia diária de mais de 30.000 barris equivalentes de petróleo, aproxi- madamente $25 \%$ dos resultados obtidos com o Proálcool, num período de 10 anos, a um custo de mais de 9 biIhões de dólares. Atualmente, a Agência está promovendo junto aos sindicatos e associações empresariais a utiliza. ção de tarifação horo-sazonal e das novas tarifas elétricas diferenciadas, Ener. gia Firme para Substituição (EFST) e Energia Temporária para Substituição (ETST) que permitem às empresas reduzir suas faturas de energia elétrica e ao setor elétrico reduzir seus investi. mentos.

Além da energia elétrica, a Agência tem trabalhando na viabilização de outros energéticos a serem utilizados principalmente a nivel local, isto é, próximo às suas fontes, nos segmentos do mercado que melhor possam absorvê-los. Is to é feito através do levantamento preliminar do mercado potencial efetivo, seguido da implantação de Projetos-Demonstração em algumas indústrias, monitorados por técnicos da Agência e, finalmente, da divulgação dos resultados obtidos a todos os interessados.

Considerando a existência de importantes excedentes de bagaço de cana no Estado de São Paulo, a Agência está desenvolvendo um programa nas regiões produtoras de açúcar e álcool, visando estimular a utilização deste insumo como combustivel industrial, principalmente para substituição de derivados de petróleo.

Conforme um planejamento previamente estabelecido foi realizado um levantamento junto a 26 indústrias localizadas na região de Ribeirão Preto, que representam um potencial de substituição da ordem de 56.000 toneladas de óleo combustivel por ano. Dentre estas empresas, foram selecionadas 3 que apresentam condições satisfatórias à uti. lização do bagaço de cana e com as quais a Agência desenvolve Projetos-Demonstração do uso eficiente e da confiabilidade deste energético.

Os resultados obtidos nesses ProjetosDemonstração serão utilizados na difusảo do uso do bagaço de cana como energético, de maneira regular, em outras empresas da região e/ou em outras regiōes do Estado onde ele seja disponivel.

A Agência está coordenando também um Programa que tem por objetivo esti. mular o aumento da oferta de madeira energética, regularizar o seu suprimento no mercado e incentivar o seu uso em certas regiões do Estado. Como primeira etapa do Programa, foi realizado um levantamento das condições de suprimento deste insumo no Estado.

Levando em consideração a disponibilidade de reflorestamentos já existentes para exploração energética, escolheu. se a região de Araçatuba/Andradina para implantação de um Projeto-Demonstração da viabilidade de comercialização de madeira energética. Para isto foram efetuados contatos, de um lado com reflorestadores, de outro com cer. ca de 40 consumidores da região, para identificação de um conjunto de usuários, junto aos quais possa ser implantado, pela Energia de São Paulo, um programa consistente de comercializacão de madeira para fins energéticos.

Ainda dentro do Programa de Substituição de derivados de petróleo, destaca-se a atuação da Agência no projeto de Substituição e Conservação de Ener. gia em Entidades Públicas que visa a substituição de derivados de petróleo por outros energéticos em entidades da Administração Pública estadual, voltadas à prestação de serviços sociais tais como hospitais, presídios, atendimentos de menores, e outros. Foi realizada uma avaliação técnica de 65 unidades consumidoras das Secretarias de Estado da Saúde, Promoção Social, Justiça e Segurança Pública, que apresentam um potencial de substituição de $4.500 \mathrm{~m}^{3} /$ ano de óleo diesel e 1.800 t/ano de óleo combustivel. Nessas 65 unidades as alternativas viáveis seriam eletricidade (em 29 delas), gás canalizado (em 14) e lenha (nas 22 outras).

Neste caso, o trabalho da Agência é dar completa assessoria às Secretarias de Estado não somente no tocante à definição de alternativas, mas, principalmente, na obtenção de recursos financeiros junto ao Governo do Estado e nos proces. sos de contratação de obras para execução das substituições.

Já estão concluídas as obras em 9 (nove) unidades das Secretarias de Estado da Promoção Social e Saúde onde, com investimentos de $\mathrm{Cr} \$ 800$ milhões, foi possível a substituição de 1.230 .000 litros/ano de óleo diesel por gás canalizado e lenha, que permitirão obter uma economia anual de $\mathrm{Cr} \$ 740$ milhões.

A Agência está conduzindo ainda um estudo de caso no Hospital Psiquiátrico de Franco da Rocha procurando substituir o óleo diesel consumido em 18 caldeiras por lenha produzida em reflorestamento do próprio hospital de modo a torná-lo autônomo em energia e incentivar o uso da mão-de-obra dos internos em programas de laborterapia. 
Para as demais unidades, estão sendo realizadas negociações com a Secretaria de Planejamento e outros órgãos estaduais e federais, visando obter recursos que possibilitem sua realização ainda este ano.

O Programa de Conservaçăo de Energia da Agência vem sendo tratado com ênfase especial, considerando tanto o interesse econômico das empresas quanto seu papel social como concessionárias de serviços públicos.

Dessa forma, entre outros projetos desse programa, destaca-se a elaboração do "Manual de Economia de Energia Elétrica no Lar" que visa a orientação do consumidor residencial quanto à meIhor utilização desse energético, o que pode levar a economias imediatas de $20 \%$ ou mais em sua conta de eletricidade, procurando incentivar ainda a redução do consumo nos horários de maior carga (ponta) do sistema elétrico, trazendo com isso benefícios diretos às concessionárias e ao Sistema Elétrico em geral. A tiragem desse manual foi de aproximadamente 1 milhão de exemplares.

Também dentro dessa diretrizes, foi realizada nos dias 27 e 28 de abril passado, no Palácio das Convençōes no Anhembi, a Feira da Energia no Lar, cujo objetivo foi mostrar à população, principalmente a de baixa renda, a correta utilização de eletrodomésticos e fogões, como fazer pequenos consertos em aparelhos domésticos e demonstrar, através de uma casa-modelo, a forma correta de se fazer a instalação elétrica em uma residéncia.

Foi ainda apresentada, em sessões corridas, durante todo o transcorrer do evento, uma peça teatral que buscava transmitir ao público, de modo alegre e direto, as formas de economia de energia no lar, dando especial atenção para a redução do consumo nos horário de ponta.

O público presente; superando as expectativas dos organizadores, foi de aproximadamente 50 mil pessoas, motivado em grande parte pela cobertura que os jornais e as emissoras de rádio e televisão deram ao evento em seus noticiários.

A afluência e o interesse demonstrados pelos consumidores é fator determinante da continuidade desse evento que será levado ainda este ano a cidade do interior do Estado e municípios da periferia da capital.

Também no âmbito do Programa de Conservação de Energia, a Agencia tem dedicado atenção especial aos Setores Comercial e Público. Neste sentido foi realizada uma auditoria energética no Edifício-Sede da Empresa Brasileira de Correios e Telégrafos (EBCT) em São Paulo, que resultou num diagnóstico detalhado do consumo de energia e na proposição de medidas de racionalização do consumo de eletricidade, principalmente nos sistemas de iluminação e condicionamento de ar.

Os edifícios que compõem a sede da EBCT apresentavam um consumo médio de $1.000 .000 \mathrm{kWh} / \mathrm{mês}$. As medidas e providências propostas foram aprovadas pela diretoria da EBCT e prevêem uma redução no consumo da ordem de $228.000 \mathrm{kWh} / \mathrm{mês}$, com uma economia de $23 \%$, praticamente sem nenhum investimento adicional.

Ainda no setor comercial, com o objetivo de orientar as administraçõs das redes de hotéis e de hospitais quanto à utilização racional de energia, a Agência elaborou manuais especificos para esses segmentos do mercado. Esses manuais, bem como a metodologia desenvolvida no projeto da $E B C T$, estão sendo divulgados a outros interessados.

No setor público, a Agência está conduzindo, em conjunto com o CEPAM Centro de Estudos e Pesquisas da Administração Municipal (Fundação Prefeito Faria Lima), um programa de Orientação aos Serviços Autónomos de Águas e Esgotos existentes em 285 mu. nicípios paulistas, procurando orientá. los, através de cursos dirigidos aos técnicos desses serviços, quanto à utilização racional de energia elétrica em suas instalações, procurando com isso reduzir a participação desse energético no custo final da água servida à população.

Entre os novos programas da Agên. cia, podemos destacar os programas de incentivo à utilização de outros energéticos alternativos como a turfa, a energia solar, o carvão mineral e a geotermia, em regiōes do Estado onde estes ener. géticos sejam disponíveis a preços competitivos.

Em conclusão, podemos dizer que a função da Agência é acompanhar sem. pre que necessário o desenvolvimento das linhas consumo-produção. Isto naturalmente envolve atenção permanente com relação às vocaçōes econômicas de cada micro-região, à introduçāo de no. vas tecnologias, ao balanço econômico do custo de cada fonte primária por região, etc. É muito mais um trabalho de apoio a quem produz ou utiliza energia do que uma ação de "empurrar" o con- sumidor para a escolha desta ou daquela forma de energia.

Tudo se torna mais fácil na medida que o próprio consumidor opte pela so. luçăó técnico-economicamente correta. Por isso, a introdução de novas tecnologias, tanto no âmbito do produtor, quanto do consumidor, é uma atividade permanente: a cada dia temos noticias de novas soluções que eventualmente podem ser aproveitadas num determinado setor de consumo ou área de fornecimento.

Cabe à Agência para Aplicação de Energia, orientar no sentido de uma maior racionalidade energética, benefi ciando cada consumidor de energia e a sociedade como um todo. 